\title{
Knowledge and Practice of Exclusive Breastfeeding Among Mothers Seen at the University of PortHarcourt Teaching Hospital
}

\author{
Yaguo Ide Lucy Eberechukwu*, Uchenwa-Onyenegecha Tochi Ada \\ Department of Paediatrics, University of Port Harcourt Teaching Hospital, Port Harcourt, Nigeria \\ Email address: \\ lucyaguolucy@gmail.com (Yaguo I. L. E.), tochiuchenwa@yahoo.com (Uchenwa-Onyenegecha T. A.) \\ ${ }^{*}$ Corresponding author
}

\section{To cite this article:}

Yaguo Ide Lucy Eberechukwu, Uchenwa-Onyenegecha Tochi Ada. Knowledge and Practice of Exclusive Breastfeeding Among Mothers Seen at the University of Port Harcourt Teaching Hospital. Advances in Materials. Vol. 6, No. 1, 2018, pp. 32-36. doi: 10.11648/j.ajhr.20180601.15

Received: September 29, 2017; Accepted: October 31, 2017; Published: March 15, 2018

\begin{abstract}
Exclusive breastfeeding for the first six months of life is a natural, cost effective and feasible intervention that promotes child survival. Exclusive breastfeeding has been promoted severally but its practice has remained poor in Nigeria. This study aims to determine the knowledge and practice of exclusive breastfeeding among mothers who bring their children to the department of Paediatrics University of Port Harcourt Teaching Hospital. This was a descriptive cross-sectional hospital based study carried out from January 2012 to December 2013. A total of three hundred mothers presenting with their children for treatment at the Department of Paediatrics outpatient clinics, emergency and children medical wards were consecutively recruited into the study. Data on demographics, marital status, socioeconomic characteristics, knowledge and practice of breastfeeding were obtained using a structured self-administered questionnaire. The respondents were aged between 18 and 55 years with a mean age of 31.59+6.6years. Most of the women were between 26-35years, majority (39\%) were aged 2530 years and majority $(89.3 \%)$ were married. Thirteen percent had no formal education while majority (63.8\%) had tertiary education. Ninety eight percent of the respondents had heard about EBF. Knowledge of the correct meaning of EBF was $91.3 \%$ while awareness of the benefits of EBF was $69.3 \%$. Thirty five (11.7\%) practiced EBF for the first 6months. More than half (57.7\%) of the respondents initiated breastfeeding within 1hour of delivery while $24.7 \%$ did so after 1 hour but within 24 hours of delivery. One hundred and twenty seven (42.3\%) of the mothers had given prelacteal feeds to their babies. Of those who gave prelacteal feeds, $8.6 \%$ gave plain water, $6.3 \%$ glucose water, and $0.3 \%$ infant formula and herbs. In conclusion, the practice of exclusive breastfeeding in this study is very low and therefore there is an urgent need to scale up programmes that will promote exclusive breastfeeding in our region.
\end{abstract}

Keywords: Knowledge, Practice, Exclusive Breastfeeding, Mothers

\section{Introduction}

Breastfeeding is a natural process necessary for optimal growth and development of infants and its benefits are well established [1,2]. Breastmilk has the appropriate balance of nutrients and immunological factors needed for survival in the formative years of life [1-3]. Exclusive breastfeeding (EBF) is defined as feeding an infant with only breastmilk and no additional food, water, or other liquids with the exception of vitamins, mineral supplements or other medicines during the first six months of life $[1,4]$. EBF is a known important determinant factor of the nutritional status of an infant and ultimately impact child survival; it provides an inexpensive complete nutrition for infants, protects them against infections and prolongs lactation amenorrhea thus increasing birth spacing [2, 3, 5]. Researchers have shown that EBF significantly protected infants from dying from infectious diseases in the first few months of life compared to those who were not exclusively breastfed [6-8]. EBF is globally recognized to be the most effective preventive intervention for ensuring child survival and this intervention alone can reduce child mortality by up to $13 \%$ in children 
under five years in the developing world [9].

World Health Organisation (WHO) and United Nations Children Fund recommends early initiation of breastfeeding within one hour of life, EBF for the first 6months of life followed by breastfeeding along with complimentary foods for up to two years of age and beyond. EBF has been encouraged and propagated by WHO/UNICEF through various ministries and baby friendly initiative $[1,10]$.

Despite strong evidence to support EBF, the practice of exclusive breastfeeding has remained suboptimal with consequent high child mortality rate in most developing countries. In Nigeria EBF practice is still below the recommendations by WHO/UNICEF, and various studies in different states have reported varied prevalence rates [11-15]. National data from NDHS 2008 and 2013 revealed a national EBF prevalence of $13 \%$ and $17 \%$ respectively $[16,17]$.

The aim of this study is to determine the knowledge and practice of exclusive breastfeeding among mothers who bring their children to the Department of Paediatrics University of Port Harcourt Teaching Hospital.

\section{Materials and Methods}

\subsection{Study Area}

The study was carried out at the Department of Paediatrics, University of Port Harcourt Teaching Hospital. The study participants were mothers presenting with their children for treatment at the outpatient clinics, emergency and children medical wards of the Paediatric Department.

\subsection{Study Design}

This was a descriptive cross-sectional hospital based study carried out from January 2012 to December 2013.

\subsubsection{Sample Size Determination}

The sample size for this study was calculated using the formula for descriptive study.

$$
\mathrm{n}=\mathrm{z}^{2}(\mathrm{pq}) / \mathrm{e}^{2}
$$

$\mathrm{n}=$ minimum sample size

$\mathrm{z}=1.96$ at $95 \%$ confidence, so that $\mathrm{z}^{2}=3.8416$

$\mathrm{p}=\mathrm{known}$ prevalence of exclusive breastfeeding (Prevalence of $82 \%$ obtained from a cross sectional survey in Western

Nigeria was used)

$\mathrm{e}=$ error margin tolerated at $5 \%=0.05$

$n=226$.

\subsubsection{Sampling Method}

The mothers were consecutively recruited until the minimum sample size was met.

\subsection{Study Instrument and Data Management}

A pre-tested structured self-administered questionnaire was used for data collection. Data on demographics, marital status, socioeconomic characteristics, knowledge and practice of breastfeeding were obtained from the mothers.
Data collected was analysed using the Statistical Package for Social Sciences (SPSS) version 20.0 software.

\subsection{Ethical Considerations}

Informed consent was obtained from the mothers prior to the onset of the study. Those mothers who declined participating were excluded. All information obtained was strictly confidential.

\section{Result}

\subsection{Socio-demographics of the Respondents}

A total of three hundred mothers participated in the study. The socio-demographic characteristics of the study population are as shown in Table1. The respondents were aged between 18 and 55 years with a mean age of $31.59 \pm 6.6$ years. Most of the child bearing women were between 26-35years, majority (39\%) were aged 25-30years while $27.3 \%$ were $31-35 y$ years and the least group were less than 20years $(0.01 \%)$. Most of them $(89.3 \%)$ were married. Thirteen percent had no formal education while majority $(63.8 \%)$ had tertiary education. Most of the respondents were engaged in skilled labour while $11.2 \%$ were house wives.

Table1. Socio-demographics of respondents.

\begin{tabular}{lll}
\hline Ages of mothers (in years) & Number & Percentage (\%) \\
\hline$<20$ & 3 & 0.01 \\
$20-25$ & 28 & 9.3 \\
$26-30$ & 117 & 39 \\
$31-35$ & 82 & 27.3 \\
$36-40$ & 36 & 12 \\
$41-45$ & 15 & 5 \\
$46-50$ & 11 & 3.7 \\
$51-55$ & 4 & 1.3 \\
Missing Age & 4 & 1.3 \\
Marital status & & \\
Married & 268 & 89.3 \\
Single & 20 & 6.7 \\
Divorced & 5 & 1.7 \\
Widowed & 6 & 2.0 \\
Separated & 1 & 0.3 \\
Educational status & & \\
None & 44 & 1.3 \\
Primary & 17 & 5.7 \\
Secondary & 82 & 27.3 \\
Tertiary & 191 & 63.7 \\
Not indicated & 6 & 2.0 \\
Occupation & & \\
Medical Practitioners & 91 & 30.4 \\
Business & 29 & 9.8 \\
Civil Servant & 25 & 13.4 \\
Accountant & 23 & 19.1 \\
Petty Trader & 34 & \\
House wife & 57 & \\
Not indicated & & \\
\hline & & \\
\hline
\end{tabular}

\subsection{Knowledge and Attitude Towards Exclusive Breastfeeding}

Table 2 shows the respondent's knowledge and attitude towards EBF. Ninety eight percent of the respondents had 
heard about EBF. Knowledge of the correct meaning of EBF was $91.3 \%$ while awareness of the benefits of EBF was $69.3 \%$.

Table2. Knowledge and attitude towards Exclusive breastfeeding.

\begin{tabular}{lll}
\hline Knowledge/Attitude & Number & Percentage \\
\hline Had heard & 295 & 98.3 \\
Knew correct meaning & 274 & 91.3 \\
Knew benefits to mother & 208 & 69.3 \\
Agree that EBF is good & 291 & 97.0 \\
Would encourage others to practice EBF & 280 & 93.3 \\
\hline
\end{tabular}

\subsection{Breastfeeding Practices of the Respondents}

Table 3 shows the breastfeeding practices of respondents. Thirty five (11.7\%) practiced EBF for the first 6months. Thirty three $(3.3 \%)$ of the respondents introduced complimentary feeds by the first month while 122 (40.9\%) introduced complimentary feeds by the fifth month. More than half $(57.7 \%)$ of the respondents initiated breastfeeding within 1 hour of delivery while $24.7 \%$ did so after 1 hour but within 24 hours of delivery. One hundred and twenty seven $(42.3 \%)$ of the mothers had given prelacteal feeds to their babies. Of those who gave prelacteal feeds, $8.6 \%$ gave plainwater, $6.3 \%$ glucose water, and $0.3 \%$ infant formula and herbs.

Table 3. Breastfeeding practices of respondents.

\begin{tabular}{|c|c|c|}
\hline Breastfeeding Practice & Number & Percentage \\
\hline Exclusive breastfeeding for first 6 months & 35 & 11.7 \\
\hline \multicolumn{3}{|l|}{ Time of commencement of complementary feeds } \\
\hline $\begin{array}{l}\text { Commencement of complementary feeds in } \\
\text { first month of life }\end{array}$ & 33 & 3.3 \\
\hline $\begin{array}{l}\text { Commencement of complementary feeds by } \\
\text { the fifth month of life }\end{array}$ & 122 & 40.6 \\
\hline $\begin{array}{l}\text { Commencement of complementary feeds by } \\
\text { the sixth month of life }\end{array}$ & 134 & 44.6 \\
\hline $\begin{array}{l}\text { Continued breastfeeding till at least two years } \\
\text { of age }\end{array}$ & 12 & 4.0 \\
\hline \multicolumn{3}{|l|}{ Initiation of Breastfeeding } \\
\hline Within 1 hour of delivery & 173 & 57.7 \\
\hline Within $>1$ hour -24 hours of delivery & 74 & 24.7 \\
\hline Pre-lacteal feeds & 127 & 42.3 \\
\hline \multicolumn{3}{|l|}{ Types of Pre-lacteal feeds } \\
\hline Plain water & 25 & 8.6 \\
\hline Glucose water & 19 & 6.3 \\
\hline Infant formula & 1 & 0.3 \\
\hline Native herbs & 1 & 0.3 \\
\hline Not indicated & 81 & 63.8 \\
\hline
\end{tabular}

\section{Discussion}

This study reveals that there was a high level of awareness about EBF among the respondents which is similar to the findings by other authors in Nigeria [14,18] and supports the aim of the Baby Friendly Hospital Initiative. This finding of high level of awareness contrasts with what was obtained in studies carried out in Northern Nigeria by Oche et al [3] in Sokoto and Illayasu et al [12] in Kano who reported a low level of awareness of $30 \%$ and $31 \%$ respectively. The observed differences between the findings from this study and that of Oche et al [3] and Illayasu et al [12] may be due to differences in the socio-cultural background and level of education of the study population. In the present study, most of the respondents had tertiary education compared to those in the studies by Oche et al [3] and Illayasu et al [12]. Most of the respondents in the present study were married and in their active reproductive periods between 26-35years as reported in similar studies $[13,19,20]$. The prevalence of EBF in this study of $11.7 \%$ for the first 6 months is comparable to the national prevalence of $13 \%$ and $17 \%$ reported by NDHS 2008 and 2013 respectively [16,17]. On the contrary, other studies in Nigeria and other developing countries reported much higher prevalence rates. In a study by Essien et al [14] in Calabar the prevalence of EBF was $60 \%$ while Okafor et al [13] in Lagos reported a prevalence of $52.9 \%$, while Oche and Umar [21] reported a prevalence of $79 \%$ in their study. Pam and Okolo [15] in Plateau state however reported a lower prevalence of $6 \%$ in their study. These are still far below the widely accepted universal coverage target of $90 \%$ [9] suggesting the need to scale up efforts towards promoting exclusive breastfeeding in Nigeria. The disparities in the prevalence rates may be attributed to differences in cultural practices and values in the different populations studied, the occupation of the respondents may also be a contributing factor. The low prevalence of EBF in this study despite that majority had tertiary education and a good number were even medical practitioners is of concern considering that these population should have better knowledge of all the benefits of EBF and thus higher practice of EBF in comparison with the respondents in the study by Oche and Umar [21] where most of them had no formal education and all were full time housewives thus giving them enough time to carry on breastfeeding. This therefore highlights that educational status and knowledge about EBF may not be good predictors of EBF practice in a mother but other factors like working conditions and other social constraints may play key roles.

In this study more than half $(57.7 \%)$ of the women initiated breastfeeding within 1 hour of delivery which is comparable with the findings in the studies by Okafor et al [13] in Lagos, Oche et al [3] in Sokoto and Anoshirike et al [11] in Enugu but lower than the $72.2 \%$ reported by Chandrashekhar et al [22] in Western Nepal, India. On the other hand, Oche and Umar [21] in Sokoto and Illayasu et al [12] in Gwale Kano in their studies obtained lower rates of $8 \%$ and $26 \%$ respectively. There is growing evidence that early initiation of breastfeeding within one hour of life reduces mortality rate in babies as late initiation of breastfeeding deprives babies from colostrums which has anti-infective properties $[6-8,23]$. The practice of prelacteal feeding in this study was high compared to those obtained from previous studies in Nigeria [24] but lower than the $77 \%$ reported in a study conducted at Bangladesh [25]. This high prevalence of prelacteal feeding highlights the need for health workers to emphasize the dangers of prelacteal feeds and clarify misconceptions about EBF among mothers. There 
is also need to educate mothers on the importance of early initiation of breastfeeding within the $1^{\text {st }}$ hour of life as recommended by WHO and UNICEF in order to improve the neonatal mortality indices in our country. The administration of water as the main prelacteal feeds noted in this study is consistent with those noted by Ibadin et al [24] in Benin but at variance with that reported in a previous study carried out by Akuse and Obinya [26] in Kaduna where infant formula was the main prelacteal feed and water the least. This difference could also be attributed to variations in the sociocultural beliefs of the subjects.

\section{Conclusion}

The practice of exclusive breastfeeding in this study was very low despite the high level of awareness and educational status of the respondents. There is need to strengthen exclusive breastfeeding campaigns and advocate that mothers continue exclusive breastfeeding after resuming work by providing crèches at work places, good working conditions and possibly extending maternity leave to 6months in order to achieve the universal acceptable coverage target of $90 \%$.

\section{References}

[1] World Health Organization: United Nations Children'sFund: Global strategy for infant and young child feeding. Geneva, Switzerland: World Health Organization; 2003.

[2] Krammer MS, Kakuma R. The optimal duration of exclusive breastfeeding: a systematic review. Adv Exp Med Biol. 2004; 554: 63-77.

[3] Oche MO, Umar AS, Ahmed H. Knowledge and practice of exclusive breastfeeding in Kware, Nigeria. Afr Health Sci. 2011;11(3):518-523.

[4] World Health Organisation Part1 Definitions. Indications for defining infant and young child feeding practices: Conclusions of a concensus meeting held 6-8 November 2007 in Washington DC USA. Available from www.whol.bdoc.who.int/publications20089789241596664eng .pdf

[5] Perez A, Labbok M, Keenan JJ. Clinical studies of the lactation amenorrhoeic method for family planning. Lancet 1992; 339: 968-970.

[6] Mullany LC, Katz J, Li YM, Khatry S K, Leclerq SC, Darmstadt GL ,Tielsch JM: Breast-feeding patterns, time to initiation, and mortality risk among newborns in southern Nepal. J Nutr 2008,138: 599-603.

[7] Singh K: The effect of colostrums on infant mortality: urban rural differentials. Health and Population 1992, 15:94-100.

[8] World Health Organization Collaborative Study Team on the role of breastfeeding on the prevention of infant mortality. Effect of breastfeeding on infant and child mortality due to infectious diseases in less developed countries: a pooled analysis. Lancet 2000: 355:451-455.

[9] Jones G, Skeketee RW, Black RE, Bhutta ZA, Morris SS. Bellagio child survival study group; Child survival II. How many child deaths can we prevent this year Lancet 2003; 362: 65-71.

[10] United Nations Children's Fund; UNICEF and the Global Strategy on infant and Young Child Feeding (GSIYCF). Understanding the past-planning the future. UNICEF working paper. Available from:http://www.unicef.org/nutrition/filesFinalReportonDistridution .pdf

[11] Anoshirike CO, Ejeogo CP, Nwosu OIC, Maduforo AN, Nnoka Kingsley O. Infant feeding practices among mothers and their infants attending maternal and child health in Enugu, Nigeria. J Biol Agric Healthc 2014; 4:130-139.

[12] Illyasu Z, Kabir M, Abubakar IS, Galadanci NA. Current knowledge and practice of exclusive breastfeeding among mothers in Gwale LGA of Kano State. Nig Med Pract 2005; 48(2): 50-55.

[13] Okafor IP, Olatona FA, Olufemi OA. Breastfeeding practices of mothers of young children in Lagos, Nigeria. Niger J Paed 2014; 41:43-47.

[14] Essien NC, Samson-Akpan PE, Ndebbio TJ, John ME. Mother's knowledge, attitudes, beliefs and practices concerning exclusive breastfeeding in Calabar, Nigeria. Afr $J$ Nurs Midwifery. 2009; 11:65-75.

[15] Pam IC, Okolo SN. Breastfeeding practices among the Fulanis in Vom, Plateau State of Nigeria. Highland Medical Journal 2012; 11:81-86.

[16] National Population Commission (NPC) [Nigeria] and ICF Macro. Nigeria Demographic and Health Survey 2008. Abuja, Nigeria: National Population Commission and ICF Macro. 2009.

[17] National Population Commission (Nigeria) and ICF International. Nigeria Demographic and Health Survey 2013. Rockville, Maryland, USA. National Population Commission and ICF International. 2014.

[18] Ukaegbu AU, Ukaegbu PO, Onyeonoro UU, Ubajaka CF. Determinants of breastfeeding among mothers in Anambra State, Nigeria. South Afr J Child Health 2011; 5:112-116.

[19] Maduforo AN, Ubah NC, Ubiakor-Okeke PN. The practice of exclusive breastfeeding by lactating women in Owerri Metropolis, Imo State, Nigeria. Glo Adv Res J Med Med Sci. 2013; 2(1):13-19.

[20] Sholeye OO, Adosede OA, Salako AA. Exclusive breastfeeding and its associated factors among mothers in Sagamu South west Nigeria. J Health Sci 2015; 5:25-31.

[21] Oche MO, Umar AS. Breastfeeding practices of mothers in a rural community of Sokoto, Nigeria. Niger Postgrad Med J. 2008; 15:101-104.

[22] Chandrashekhar TS, Joshi HS, Shankar PR, Binu VS, Rana MS. Breastfeeding initiation and determinants of Exclusive breastfeeding- a questionnaire survey in an urban population of Western Nepal. Public Health Nutr 2007; 10:192-197.

[23] Edmond KM, Zandoh C, Quigley MA, Amenga-Etego S, Owusu-Agyei S, Kirkwood BR: Delayed breastfeeding initiation increases risk of neonatal mortality. Pediatrics 2006,117:e380-e386.

[24] Ibadin OM, Ofili NA, Monday P, Nwajei CJ. Prelacteal feeding practices among lactating mothers in Benin City, Nigeria. Niger J Paed 2013; 40:139-144. 

Among Mothers Seen at the University of Port Harcourt Teaching Hospital

[25] Ahmed FU, Rahman ME, Alam MS. Prelacteal feeding: influencing factors and relation to establishment of lactation. Bangledesh Med Res Counc Bull 1996; 22:60-64.
[26] Akuse RM, Obinya EA. Why healthcare workers give prelacteal feeds. Eur J Clin Nutr 2002; 56:729-734. 